\title{
Pore Refinement Action of GGBFS and Fly Ash on the Primary and Secondary Capillary Imbibition Rates of Concrete
}

\author{
Natalia M. Alderete ${ }^{1}$, Yury A. Villagrán-Zaccardi ${ }^{2}$ and Nele De Belie ${ }^{1}$ \\ ${ }^{1}$ Magnel Laboratory for Concrete Research, Ghent University, Technologiepark-Zwijnaarde 60, \\ 9052-Gent, Belgium, nataliamariel.alderete@ugent.be, nele.debelie@ugent.be \\ ${ }^{2}$ LEMIT, CONICET, Av. 52 entre 121 y 122 s/n, B1900AYA-La Plata, Argentina, \\ yuryvillagran@conicet.gov.ar
}

\begin{abstract}
Capillary imbibition is a transport phenomenon occurring in concrete structures exposed to weathering, frequently in direct connection with the resistance against different deterioration processes. This property depends on the volume and connectivity of pores. For ground granulated blast-furnace slag (GGBFS) and fly ash blended concrete mixes, the pore refining action of these supplementary cementitious materials plays a positive role in the disconnection of the capillary porosity and consequent reduction of the capillary imbibition rate. Moreover, for this particular transport process, primary and secondary transport rates can be defined in connection with different driving mechanisms. This allows a complementary description of the pore structure of concrete. In this paper, blended concrete mixes were prepared by substituting 20, 40 and $60 \%$ of OPC by GGBFS, and 20, 30 and $40 \%$ of OPC by fly ash. The pore structure of these concretes is assessed by water absorption under vacuum and mercury intrusion porosimetry after curing periods of 28 and 90 days. Long-term capillary imbibition tests were also performed and primary and secondary imbibition rates are computed by a novel approach that considers their linear evolution with the fourth root of time. Results show the refinement action of GGBFS and fly ash by a softening in the transition stage between the primary and secondary imbibition periods. A low water flow rate is consequently correlated with the increased tortuosity of samples.
\end{abstract}

Keywords: Sorptivity, Supplementary Cementitious Materials, Pore Structure, Imbibition.

\section{Introduction}

Sorptivity is a widely used durability index of concrete. The quantification of the rate of water imbibition by capillarity in concrete describes the pore connectivity of cementitious materials. Previous work has shown that primary and secondary imbibition rates can be used for describing the pore structure on the basis of their corresponding driving mechanism.

The most usual assessment method considers the relation between water uptake and the square root of time, but it faces the significant difficulty of the lack of linearity of this relationship for the case of cementitious materials. This is usually referred as anomalous sorptivity (Hall, 2007; Küntz and Lavallée, 2001; Lockington and Parlange, 2003; Villagrán Zaccardi et al., 2017). A comprehensive analysis of this analomaly led to the proposal of a new approach considering the fourth root of time, which was validated with experimental data in the short term (Villagrán Zaccardi et al., 2017). The new model considers the swelling of the C-S-H gel as the main cause for the anomalous behaviour. Physical evidence of this swelling was recently presented in (Alderete et al., 2019b), where the volumetric stability of mortar and concrete samples was registered using strain gauges. 
During long-term exposure of samples, water uptake further continues at a very low rate even after the capillary rise has covered the full height of samples (Alderete et al., 2019a; Bentz et al., 2001; Castro et al., 2011; Hall and Hoff, 2009; Kaufmann and Studer, 1995; Spragg et al., 2011). A secondary imbibition period for the water ingress driven by diffusion into the finest pores of the cementitious matrix can be therefore defined. Allegedly, this process starts as soon as the material makes contact with water, but it is initially masked by the capillary action which dominates the water flow during the primary imbibition. The secondary capillary imbibition has been presented as a convenient complementary descriptor of the transport properties of cementitious materials (Henkensiefken et al., 2009; Kurtis et al., 2016; Liu and Hansen, 2016; Wei et al., 2017). Both primary and secondary mechanisms should be considered for describing the whole moisture transport during imbibition.

In this paper, capillary imbibition tests were conducted for 17 weeks on concrete mixes with and without ground granulated blast furnace slag and fly ash to determine the primary and secondary capillary imbibition rates. These transport parameters are compared with the pore size distribution obtained by mercury intrusion porosimetry (MIP).

\section{Materials and Methods}

Concrete mixes were designed with a water to binder ratio $(\mathrm{w} / \mathrm{b})$ of 0.45 . OPC type CEM I $42.5 \mathrm{~N}$, ground granulated blast furnace slag (SB), and fly ash (FA) were used supplementary cementitious materials (SCMs) in partial replacement of OPC in proportions of 20, 40 and 60 and 20, 30 and 40\%, respectively. A reference mix with only OPC as binder was
Table 1 displays the properties of the binders, including composition, density,
size distribution (obtained by laser diffrectometry with optimal optical parameter
suggested in (Alderete et al., 2016)). Mix proportions, slump, air content, and c
strength are provided in Table 2. The mixes were named based on the binder

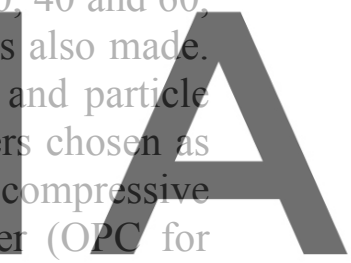
control, SB, and FA for the blends) and the weight percentage of cement replacement. To

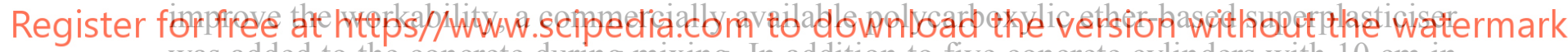
was added to the concrete during mixing. In addition to five concrete cylinders with $10 \mathrm{~cm}$ in diameter, three $10 \mathrm{~cm}$ cubes for compressive strength were also cast for each mix and cured in a conditioned room at $20{ }^{\circ} \mathrm{C} \pm 2{ }^{\circ} \mathrm{C}$ and $95 \% \pm 5 \% \mathrm{RH}$ for 28 and 90 days.

Table 1. Properties of OPC, SB, and FA.( $\mathrm{nd}=$ not determined, LOI $=$ loss on ignition $)$.

\begin{tabular}{|c|c|c|c|c|c|c|c|c|c|c|c|c|}
\hline Properties & \multicolumn{4}{|c|}{$\mathrm{OPC}$} & \multicolumn{4}{|c|}{ SB } & \multicolumn{4}{|c|}{ FA } \\
\hline \multirow{6}{*}{$\begin{array}{c}\text { Chemical } \\
\text { composition } \\
(\%)\end{array}$} & $\mathrm{CaO}$ & 64.67 & $\mathrm{~S}$ & nd & $\mathrm{CaO}$ & 38.34 & $\mathrm{~S}$ & 1.4 & $\mathrm{CaO}$ & 3.02 & $\mathrm{~S}$ & nd \\
\hline & $\mathrm{SiO}_{2}$ & 20.74 & $\mathrm{Fe}_{2} \mathrm{O}_{3}$ & 1.52 & $\mathrm{SiO}_{2}$ & 33.7 & $\mathrm{Fe}_{2} \mathrm{O}_{3}$ & 0.43 & $\mathrm{SiO}_{2}$ & 54.19 & $\mathrm{Fe}_{2} \mathrm{O}_{3}$ & 7.92 \\
\hline & $\mathrm{MgO}$ & 0.95 & $\mathrm{~K}_{2} \mathrm{O}$ & 0.77 & $\mathrm{MgO}$ & 8.18 & $\mathrm{~K}_{2} \mathrm{O}$ & 0.34 & $\mathrm{MgO}$ & 1.92 & $\mathrm{~K}_{2} \mathrm{O}$ & 3.38 \\
\hline & $\mathrm{Al}_{2} \mathrm{O}_{3}$ & 4.91 & $\mathrm{MnO}$ & nd & $\mathrm{Al}_{2} \mathrm{O}_{3}$ & 11.36 & $\mathrm{MnO}$ & 8.18 & $\mathrm{Al}_{2} \mathrm{O}_{3}$ & 23.5 & $\mathrm{MnO}$ & nd \\
\hline & $\mathrm{Na}_{2} \mathrm{O}$ & 0.27 & $\mathrm{Cl}^{-}$ & 0.07 & $\mathrm{Na}_{2} \mathrm{O}$ & 0.35 & $\mathrm{Cl}^{-}$ & 0.01 & $\mathrm{Na}_{2} \mathrm{O}$ & 0.39 & $\mathrm{Cl}^{-}$ & $<0.01$ \\
\hline & $\mathrm{SO}_{3}$ & 2.96 & LOI & nd & $\mathrm{SO}_{3}$ & 0.03 & LOI & 0.16 & $\mathrm{SO}_{3}$ & 0.94 & LOI & 1.84 \\
\hline Density $\left(\mathrm{g} / \mathrm{cm}^{3}\right)$ & \multicolumn{4}{|c|}{3.11} & \multicolumn{4}{|c|}{2.88} & \multicolumn{4}{|c|}{2.14} \\
\hline $\begin{array}{c}\text { Particle size } \\
\mathrm{dv} 10 / 50 / 90(\mu \mathrm{m})\end{array}$ & \multicolumn{4}{|c|}{$4.9 / 20.1 / 58.5$} & \multicolumn{4}{|c|}{$1.8 / 13.9 / 35.0$} & \multicolumn{4}{|c|}{$0.4 / 10 / 61.7$} \\
\hline
\end{tabular}


Natalia M. Alderete, Yury A. Villagrán-Zaccardi and Nele De Belie

Table 2. Nomenclature, mix composition, air content and slump of the studied concrete mixes.

\begin{tabular}{cccccccc}
\hline & OPCc & SB20c & SB40c & SB60c & FA20c & FA30c & FA40c \\
\hline Cement - CEM I 42.5 N $\left(\mathrm{kg} / \mathrm{m}^{3}\right)$ & 342 & 274 & 205 & 137 & 274 & 239 & 205 \\
SCM $\left(\mathrm{kg} / \mathrm{m}^{3}\right)$ & 0 & 68 & 137 & 205 & 68 & 103 & 137 \\
Water $\left(\mathrm{kg} / \mathrm{m}^{3}\right)$ & 154 & 154 & 154 & 154 & 154 & 154 & 154 \\
Sand $\left(\mathrm{kg} / \mathrm{m}^{3}\right)$ & 865 & 860 & 860 & 860 & 860 & 860 & 855 \\
Gravel 2/8 $\left(\mathrm{kg} / \mathrm{m}^{3}\right)$ & 500 & 497 & 495 & 493 & 497 & 493 & 490 \\
Gravel 8/16 $\left(\mathrm{kg} / \mathrm{m}^{3}\right)$ & 540 & 535 & 535 & 535 & 535 & 535 & 530 \\
\hline Air content $(\%)$ & 2.1 & 2.4 & 2.1 & 2.3 & 2.8 & 2.3 & 2.4 \\
Slump $(\mathrm{mm})$ & 70 & 70 & 100 & 120 & 70 & 100 & 150 \\
Compressive strength 28d $(\mathrm{MPa})$ & 50.6 & 42.6 & 32.6 & 32.2 & 50.1 & 50.8 & 48.8 \\
\hline
\end{tabular}

The top halves of the five cylinders were used to determine water absorption by immersion. First, samples were submitted to vacuum for $2 \mathrm{~h}$ and then water was drawn into the vacuum chamber until the sample became fully immersed. After $24 \mathrm{~h}$ samples were removed and the saturated weight was registered. Then, samples were subjected to drying in an oven at $105^{\circ} \mathrm{C}$. Finally, water absorption was calculated from the difference between the saturated weight and the dry weight, relative to the dry weight.

The samples for MIP were approximately $125 \mathrm{~mm}^{3}$, obtained from the core of one cylinder

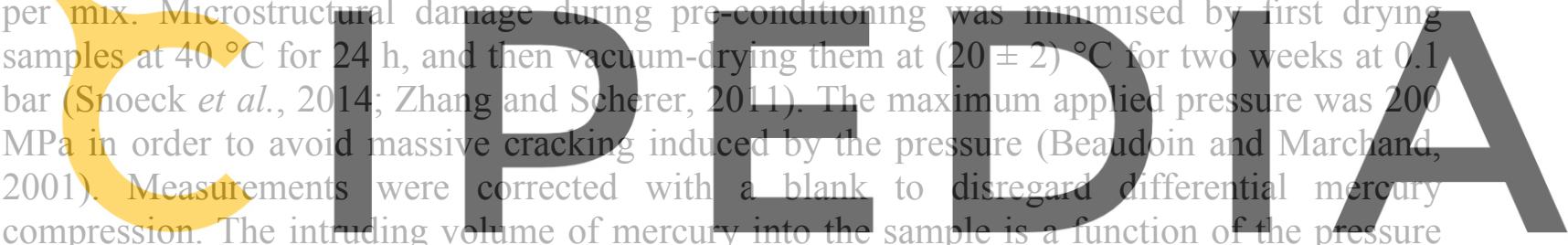
increase. Results are interpreted with the theoretical simplified model of cylindrical pores and

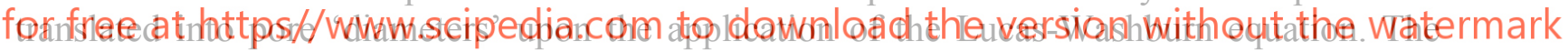
surface tension and contact angle considered for these computations were $0.482 \mathrm{~N} / \mathrm{m}$ and $142^{\circ}$ ( $\mathrm{Ma}, 2014)$, respectively. Qualitative contrasts are finally possible by comparing the threshold diameter $\left(\mathrm{d}_{\mathrm{th}}\right)$ and intrudable pore volume $\left(\phi_{\text {in }}\right)(\mathrm{Ma}, 2014)$. The calculation of $\mathrm{d}_{\text {th }}$ was made by the tangent method, and therefore denoted as $d_{\mathrm{tg}}$ (Liu and Winslow, 1995), corresponding to the intersection of tangent lines on the cumulative distribution curve at the smallest diameter that did not exhibit significant intrusion and the largest diameter that did. The range of the points to be fitted was determined by the analysis of the second derivative in the differential curve. Furthermore, according to the cumulative curve shape obtained, it is possible to make inferences about the presence of choke points.

The tested samples for the long-term capillary imbibition tests were obtained by sawing the section between 3 and $8 \mathrm{~cm}$ from the base of the five cylinders. Samples were laterally covered with aluminum-butyl tape to ensure one dimensional flow. The preconditioning procedure consisted in $72 \mathrm{~h}$ immersion in water and then drying in an oven at $50{ }^{\circ} \mathrm{C}$ until mass decrease was lower than a mass fraction of $0.1 \%$ within $24 \mathrm{~h}$. The capillary imbibition test consisted in putting the samples in contact with water, with an immersion depth of $(3 \pm 1)$ $\mathrm{mm}$. Water evaporation was avoided by putting a lid on top of the water container. The water 
level was checked regularly and the immersion depth was kept at $(3 \pm 1) \mathrm{mm}$ during the whole testing period. Samples of OPCc and FA20c mixes with 28 days of curing were the first ones to be tested, with testing periods up to 10 weeks. Based on these results, it was decided to continue the measurements for the capillary imbibition tests on the rest of samples up to 17 weeks to obtain a larger amount of data for the secondary period than for the first data series. In this manner, a more complete description of the secondary period was achieved in those cases. Measurements were performed after exposure periods of $0.5 \mathrm{~h}, 1 \mathrm{~h}, 2 \mathrm{~h}, 3 \mathrm{~h}, 4$ $\mathrm{h}, 5 \mathrm{~h}, 6 \mathrm{~h}$, and $24 \mathrm{~h}$ and after that every $24 \mathrm{~h}$ during the first week, once a week during the first two months, and once a month until 4 months.

\section{Results and Discussion}

Figure 1 displays the results of relative water absorption of the mixes at 28 and 90 days. At 28 days, values of water absorption of all SB mixes are higher than the OPCc mix. However, at 90 days, mixes SB20c and SB40c had lower water absorption than OPCc at 90 days. Values of water absorption at 28 days increased slightly with the FA content. At 90 days, FA20c and FA30c show similar results as OPCc, but the higher replacement in FA40c does not allow to compensate the dilution effect.
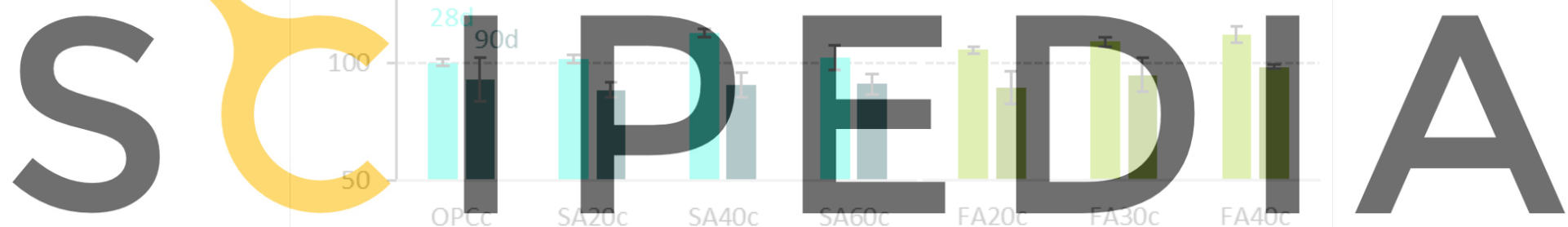

Register for Ffree at a Relative open porosity and relative water absorptign of OPCc, SB and FA concrete mixes at 28 and g0 days.

The cumulative mercury intruded volume curves of SB and FA mixes at 28 and 90 days

are presented in Figure 2, with the indication of the $\Phi_{\text {in }}$ and $d_{\operatorname{tg}}$ of each mix. Results reveal the refinement action of SB with time. All mixes had a reduction of $\phi_{\text {in }}$ between $16 \%$ and $26 \%$ after 90 days. Accordingly, $d_{t g}$ values were reduced from 28 to 90 days. For FA mixes, results indicate the slower reaction of FA in comparison with $\mathrm{SB}$, as indicated by reactivity tests (Alderete, 2018). Although all FA mixes have a lower $\phi_{\text {in }}$ at 90 days than at 28 days, the reduction is around half of that found for concrete mixes with SB. In fact, FA40c at 90 days displays a higher value than SB60c at 28 days. This shows that even with a lower amount of replacement $(40<60)$ and with more time to react $(90>28)$, FA does not compensate the clinker dilution as well as SB. Values of $\mathrm{d}_{\mathrm{tg}}$ are in agreement with this as well, as they are higher for FA concrete mixes than SB mixes at 90 days. 
Intrudable volume

$\left(\mathrm{mm}^{3} / \mathrm{g}\right)$

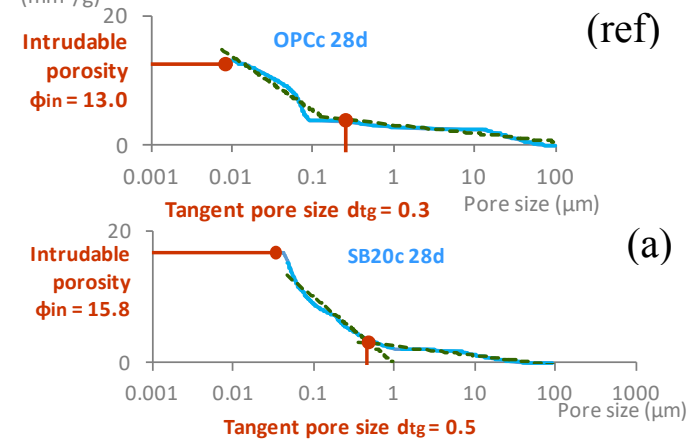

(ref)
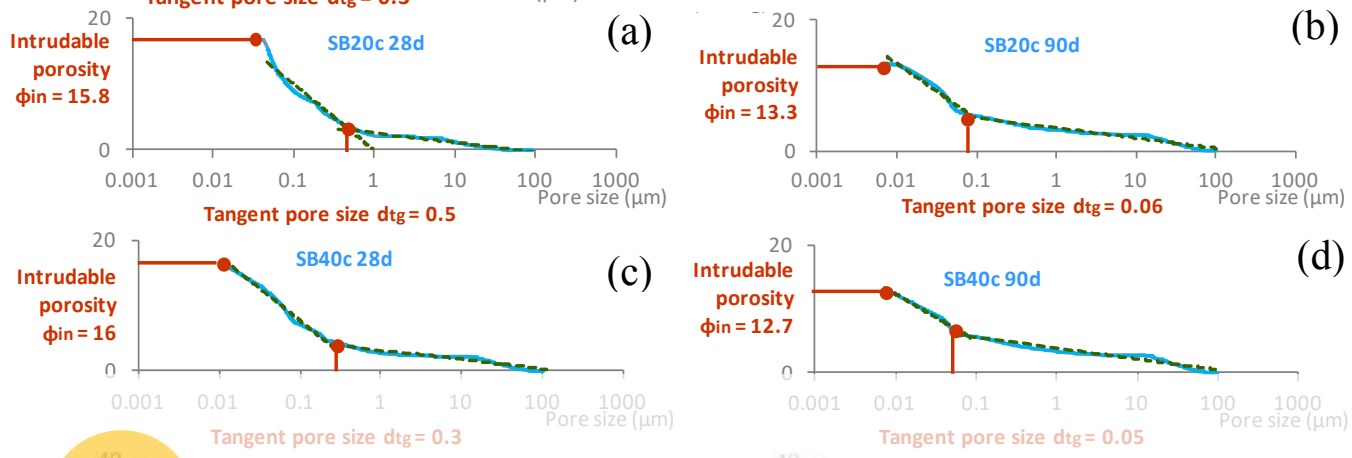

(e)

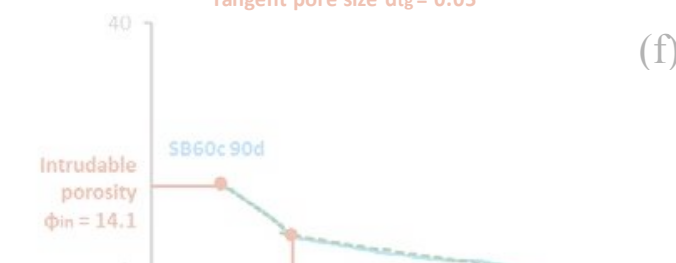

(f)
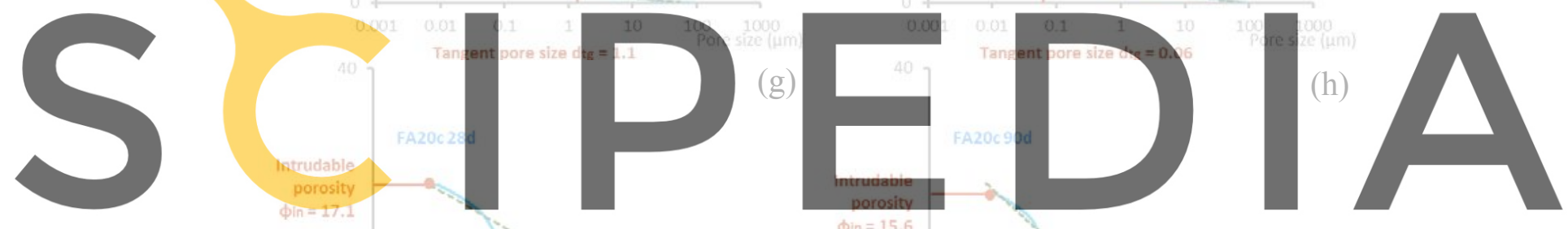

Register for free at https//www.scipedia.com to download the version without the watermark
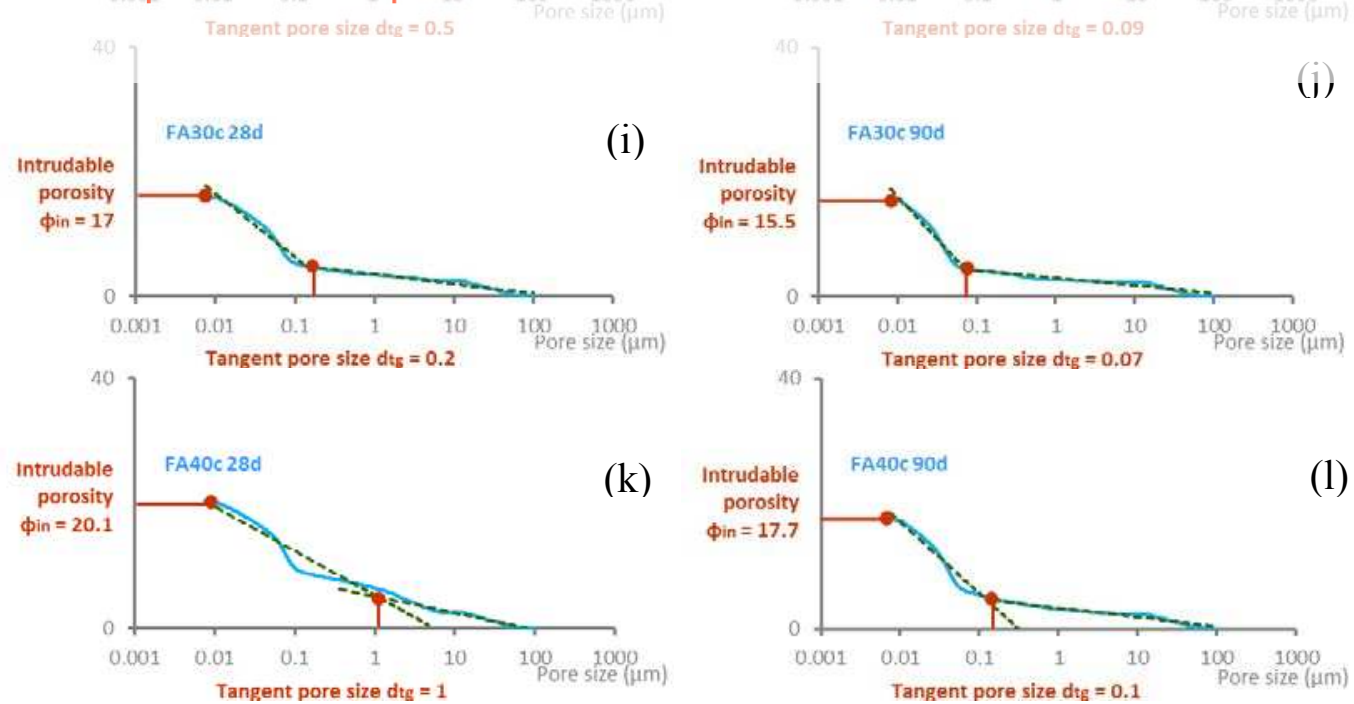

Figure 2. MIP curves of OPCc at 28 (ref), SB20c at 28 (a) and 90 (b), SB40c at 28 (c) and 90 (d), SB60c at 28 (e) and 90 (f), FA20c at $28(\mathrm{~g})$ and $90(\mathrm{~h})$, FA30c at 28 (i) and $90(\mathrm{j})$, and FA40c at $28(\mathrm{k})$ and 90 (l) days. 
Results for the capillary imbibition of the mixes are shown in Figure 3. Two periods, primary and secondary, and a transition period in between, are observed. The primary imbibition period takes place within 1 and 3 weeks, for samples tested at 28 days and 90 days, respectively. Error bars represent the standard deviation $(n=5)$ and are marked in all graphs, but, as the variability was very small, some error bars are not visible because they are smaller than the marker. The capillary imbibition rate (CIR) is computed as the slope of the fitting line during the first week: $\mathrm{CIR}_{1 \mathrm{w}}$ (for 28 days); and during the first 3 weeks: $\mathrm{CIR}_{3 \mathrm{w}}$ (for 90 days). The secondary capillary imbibition rate is computed as the slope of the fitting line after the transition period: $\mathrm{sCIR}_{1 \mathrm{w}}$ (for 28 days); and $\mathrm{sCIR}_{3 \mathrm{w}}$ (for 90 days). The corresponding coefficients of determination are shown in the graphs. The transition period is highlighted in the graphs, where the difference between the primary and the secondary periods is less marked for blended than control concrete.
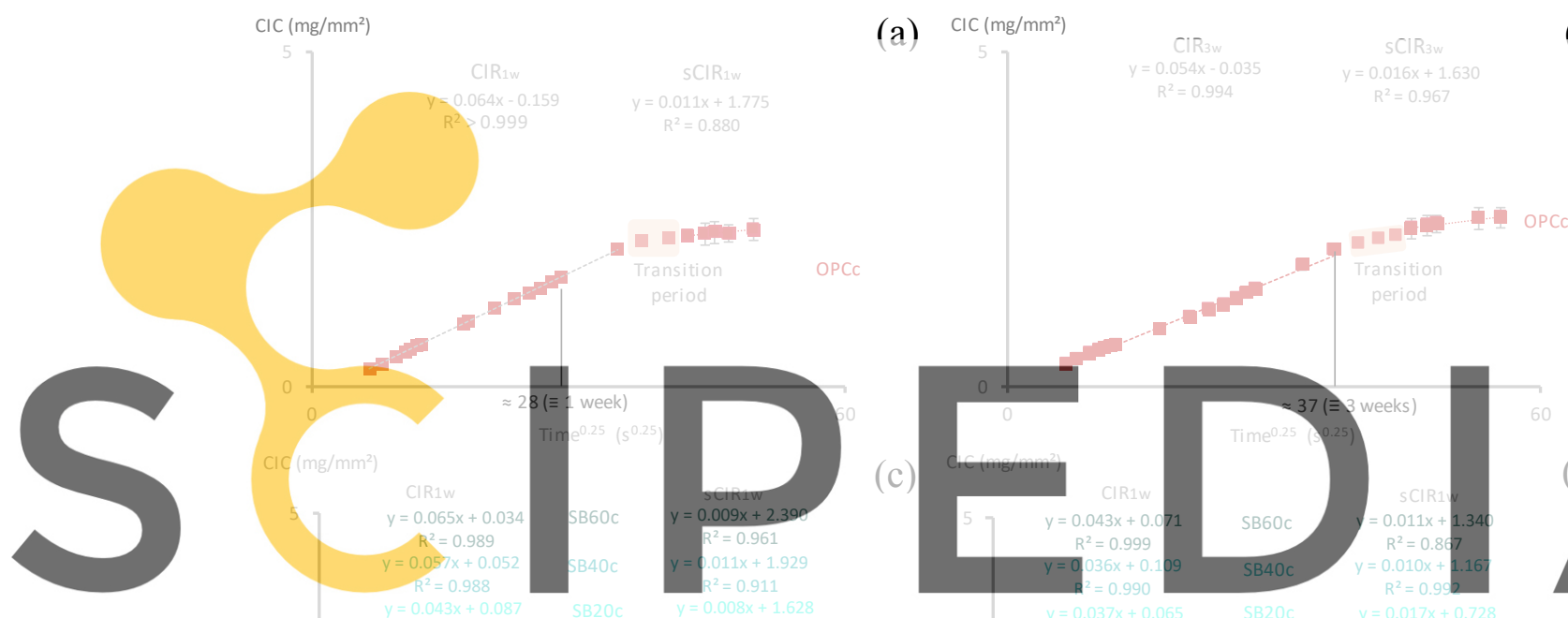

(b)

Register for free at https//www.scipedia.com to download the version without the watermark
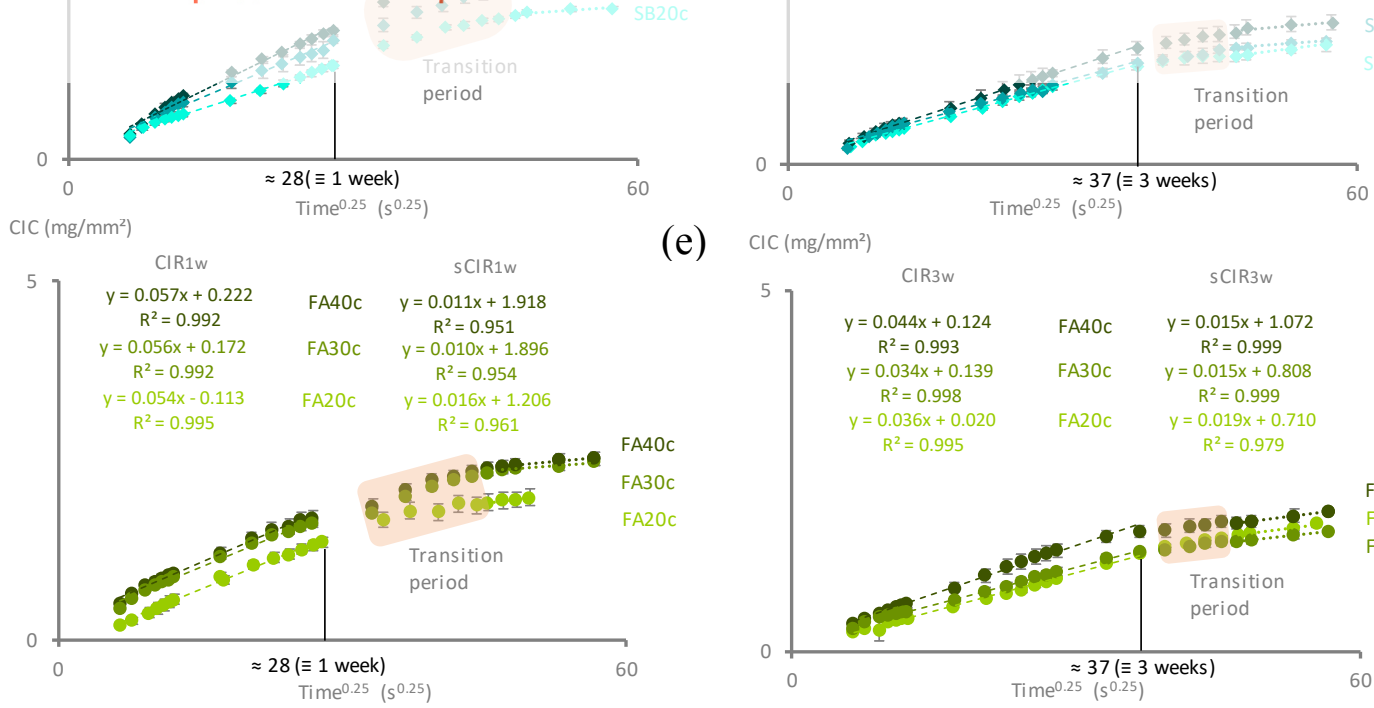

(e)

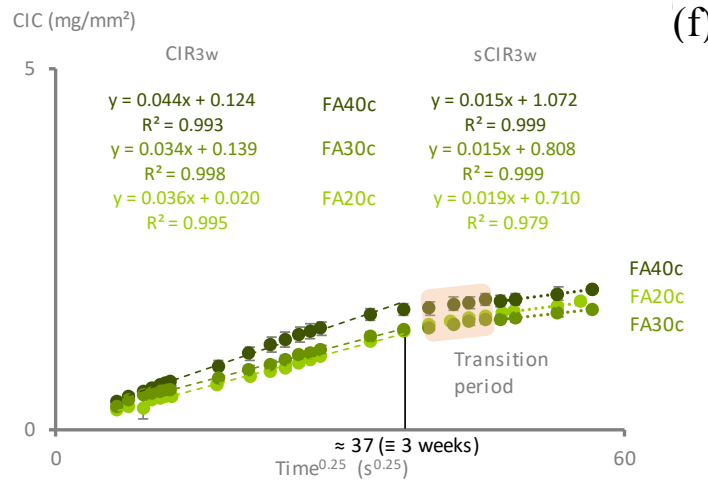

Figure 3. Long-term capillary water uptake results of OPCc at 28 (a) and 90 (b), SB at 28 (c) and 90 (d), and FA at 28 (e) and 90 (f) days. 
Pore refinement due to the action of the SCMs led to a decrease in $\mathrm{d}_{\mathrm{tg}}$ in the range of 0.2 to $1 \mu \mathrm{m}$ at 28 days, to the range of 0.05 to $0.1 \mu \mathrm{m}$ at 90 days, which corresponds to a decrease in the CIR from the range of 0.048 to $0.065 \mathrm{mg} \cdot \mathrm{mm}^{-2} \cdot \mathrm{s}^{-0.25}$ to the range of 0.034 to 0.044 $\mathrm{mg} \cdot \mathrm{mm}^{-2} \cdot \mathrm{s}^{-0.25}$. This correlation is in contrast with the values of $\phi \mathrm{in}$, which are not reflecting so well the refinement action of the SCMs. Contrarily, the SCIR does not show a clear connection with the MIP parameters, and this transport parameter is likely linked with the content of C-S-H in each mix and the gel pores. Additional research in this regard seems valuable. Furthermore, blended concrete mixes had a more marked transition period and lower imbibition rate at 90 days in comparison with 28 days, which indicates a lower flow rate due to their increased tortuosity.

\section{Conclusions}

The long-term exposure of unsaturated samples involves additional water uptake after the capillary rise has covered the total height of samples. This is a process that occurs at a much slower rate than the short-term capillary imbibition, and it can be related to a secondary transport through the finest range of pores. Long-term capillary imbibition tests in blended concretes manifested the existence of primary and secondary periods. Both periods display increasing water uptake proportional to $t^{0.25}$.

The pore refinement action of ground granulated blast-furnace slag and fly ash was reflected in the comparable reduction of the CIR and $d_{t g}$ parameters. In second term, $\phi_{\text {in }}$

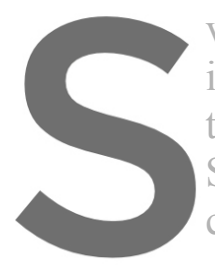
values were reduced from 28 to 90 days, but the correlation is imbibition. The likely than a reduction in poro SCMs. In this case, the content and its characteristic porosity.

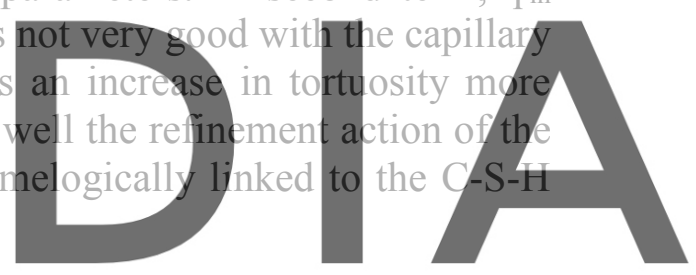

Acknowledgements

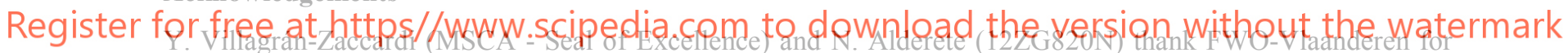
the financial support. Financial support from ANPCyT (PICT 2017-0091 Prest BID) is also appreciated.

\section{ORCID}

Natalia Alderete: https://orcid.org/0000-0001-7967-1955

Yury Villagrán-Zaccardi: https://orcid.org/0000-0002-0259-7213

Nele De Belie: https://orcid.org/0000-0002-0851-6242

\section{References}

Alderete, N. M. (2018). Microstructure of mortar and concrete with supplementary cementitious materials: relation with the capillary imbibition phenomenon, $\mathrm{PhD}$ Thesis, UGhent and UTN.

Alderete, N. M., Villagrán-Zaccardi, Y. A. and De Belie, N. (2019a). Mechanism of Long-Term Capillary Water Uptake in Cementitious Materials, Cement \& Concrete Composites, submitted.

Alderete, N. M., Villagrán-Zaccardi, Y. A. and De Belie, N. (2019b). Physical evidence of swelling as the cause of anomalous capillary water uptake by cementitious materials, Cement and Concrete Research, 120, 256266. https://doi.org/10.1016/j.cemconres.2019.04.001

Alderete, N. M., Villagrán Zaccardi, Y. A., Dos santos Coelho, G. S. and De Belie, N. (2016). Particle size distribution and specific surface area of SCMs compared through experimental techniques. In: Proceedings of the International RILEM Conference on Materials, Systems and Structures in Civil Engineering, Lyngby, 
Denmark, 61-72.

Beaudoin, J. J. and Marchand, J. (2001). Pore Structure. In: Handbook of Analytical Techniques in Concrete Science and Technology, 528-628. https://doi.org/10.1016/B978-0-8155-1437-4.50017-5

Bentz, D. P., Ehlen, M. A., Ferraris, C. F. and Garboczi, E. J. (2001). Sorptivity-based service life predictions for concrete pavements. In: Proc. of the 7th International Conference on Concrete Pavements, Orlando (FL), 1, 9-13.

Castro, J., Bentz, D. and Weiss, J. (2011). Effect of sample conditioning on the water absorption of concrete. Cement and Concrete Composites, 33(8), 805-813. https://doi.org/10.1016/j.cemconcomp.2011.05.007

Hall, C. (2007). Anomalous diffusion in unsaturated flow: Fact or fiction? Cement and Concrete Research, 37, 378-385. https://doi.org/10.1016/j.cemconres.2006.10.004

Hall, C. and Hoff, W. (2009). Water transport in brick, stone and concrete. CRC Press, Boca Raton. https://doi.org/10.1520/CCA10518J

Henkensiefken, R., Castro, J., Bentz, D., Nantung, T. and Weiss, J. (2009). Water absorption in internally cured mortar made with water-filled lightweight aggregate. Cement and Concrete Research, 39(10), 883-892. https://doi.org/10.1016/j.cemconres.2009.06.009

Kaufmann, J. and Studer, W. (1995). One-dimensional water transport in covercrete - application of nondestructive methods. Materials and Structures, 28(2), 115-124

Küntz, M. and Lavallée, P. (2001). Experimental evidence and theoretical analysis of anomalous diffusion during water infiltration in porous building materials. Journal of Physics D: Applied Physics, 34, 2547-2554

Kurtis, K. E., Burris, L. and Alapati, P. (2016). Consider Functional Equivalence : A (Faster) Path to Upscaling Sustainable Infrastructure Materials Compositions. In Proc. of the 1st International Conference on Grand Challenges in Construction Materials, 8 p.

Liu, Z. and Hansen, W. (2016). A geometrical model for void saturation in air-entrained concrete under continuous water exposure. Construction and Building Materials, 124, 475-484. https://doi.org/10.1016/j.conbuildmat.2016.07.113

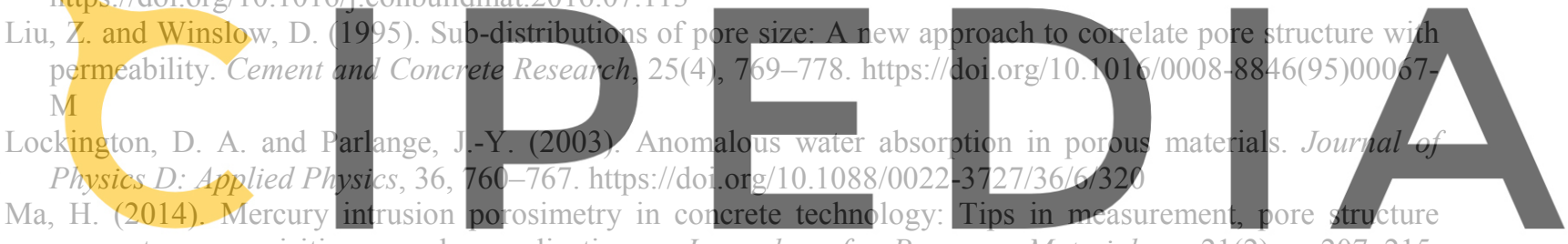
parameter acquisition and application. Journal of Porous Materials, 21(2), $207-215$.

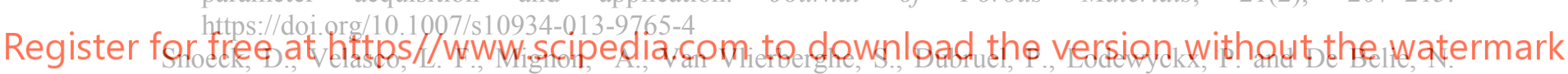
(2014). The influence of different drying techniques on the water sorption properties of cement-based materials. Cement and Concrete Research, 64, 54-62. https://doi.org/10.1016/j.cemconres.2014.06.009

Spragg, R. P., Castro, J., Li, W., Pour-Ghaz, M., Huang, P.-T. and Weiss, J. (2011). Wetting and drying of concrete using aqueous solutions containing deicing salts. Cement and Concrete Composites, 33(5), 535542. https://doi.org/10.1016/J.CEMCONCOMP.2011.02.009

Villagrán Zaccardi, Y. A., Alderete, N. M. and De Belie, N. (2017). Improved model for capillary absorption in cementitious materials: Progress over the fourth root of time. Cement and Concrete Research, 100, $153-165$. https://doi.org/10.1016/j.cemconres.2017.07.003

Wei, Z., Falzone, G., Wang, B., Thiele, A., Puerta-Falla, G., Pilon, L., Neithalath, N. and Sant, G. (2017). The durability of cementitious composites containing microencapsulated phase change materials. Cement and Concrete Composites, 81, 66-76. https://doi.org/10.1016/j.cemconcomp.2017.04.010

Zhang, J. and Scherer, G. W. (2011). Comparison of methods for arresting hydration of cement. Cement and Concrete Research, 41(10), 1024-1036. https://doi.org/10.1016/j.cemconres.2011.06.003 